\title{
Maurício Meireles - Perfil biográfico In: Maura Lopes Cançado - Hospício é Deus, Diário I
} Belo Horizonte: Autêntica, 2015

Anna Flávia Dias Salles ${ }^{1}$

Maura Lopes Cançado (1929-1993) voltou à peia da recepção literária desde o festejável relançamento, pela editora Autêntica, de suas duas obras, Hospício é Deus, Diário I e O sofredor do ver, em fins de 2015. Antes disso, seus livros eram apenas encontrados em sebos a preços praticamente inacessíveis.

Contudo, pouco se falou sobre o perfil biográfico, escrito pelo jornalista Maurício Meireles, que acompanha ambos os volumes como posfácio. Tal perfil figura como um paratexto importante, que tem por objetivo reapresentar a escritora ao público, após mais de duas décadas do último relançamento de seu diário, pelo Círculo do Livro, em 1991.

No referido perfil biográfico, Maura é ignorada como escritora e reintroduzida ao leitor como louca e criminosa. O texto tem como base o laudo psiquiátrico que instruiu o processo contra ela pelo assassinato de uma companheira de internação em instituição psiquiátrica em 1972. Quatro décadas depois, a escritora é novamente apresentada ao público a partir de excertos do documento usados como epígrafes, dez ao todo, substituindo intertítulos, presidindo às ideias que as seguem, o que equivale a dizer, presidindo ao perfil da autora. Enunciadas sem quaisquer ressalvas críticas, as únicas citações recuadas no corpo do texto são também provenientes de trechos do laudo produzido por peritos da burocracia jurídica e psiquiátrica dos chamados anos de chumbo no Brasil.

Em nota de pé de página, Meireles informa como conseguiu ter acesso ao processo judicial e que sua primeira publicação teria se dado na tese de doutorado de Maria Luísa Scaramella, Narrativas e sobreposições: notas sobre Maura Lopes Cançado (2010). No entanto, o jornalista ignorou o exame crítico depurado do documento feito pela pesquisadora que, em ponto fulcral, identifica que as

\footnotetext{
${ }^{1}$ Mestre em estudos literários pela Universidade Federal de Minas Gerais (UFMG), Belo Horizonte, MG, Brasil. Đorcid.org/0000-0003-2432-845X. E-mail: annaflavona@gmail.com
} 
"condutas desviantes" percebidas pelos peritos em Maura são remontadas segundo a necessidade de se construir uma trajetória coerente que pudesse oferecer suporte à decisão judicial sobre o crime. Dessa forma, como um fantasma, o laudo parece ter emergido de velhos arquivos burocráticos sem encontrar nenhuma resistência crítica por parte de Meireles.

Se não se buscava a escritora no laudo, tampouco isso ocorre no perfil biográfico, que também pode ser percebido como um anedotário sobre Maura, uma reunião de casos e peripécias da "louca ou excêntrica - no começo, ninguém sabia direito", conforme a descreve Meireles (2015, p. 203), contados aqui e ali por familiares, escritores, nos jornais, pela própria Maura no diário, em entrevistas ou em cartas, ou até mesmo disseminados em algumas obras literárias. Casos que o jornalista filtra e dos quais se apropria, com o aval dos peritos dos anos 1970 alimentando, com seu texto, a lenda que parece querer cercar a autora.

Meireles usa variados epítetos para se referir à Maura, entre os quais "figura ambígua", "figura boquirrota", "moça de cabelos volumosos dada a arroubos", "mulher baixinha", "personalidade excêntrica", "personalidade exuberante" (adjetivo acompanhado pela ressalva "para dizer o mínimo"), "dada a gestos extravagantes", "não muito equilibrada", "moça brilhante", "moça não propriamente bonita", além dos já supracitados "louca ou excêntrica".

A colaboração de Maura Lopes Cançado, entre 1956 e 1964, ao Suplemento Dominical do Jornal do Brasil, semanário dedicado a pensar a efervescência das artes e da literatura de vanguarda de então no país, lugar de repercussão de polêmicas importantes na cena cultural brasileira como o movimento neoconcreto carioca, é tida como apadrinhamento por parte do editor do tabloide, Reynaldo Jardim. Meireles se refere a este como "o protetor de Maura", que, diz o jornalista de passagem, "andava solta pelo Rio de Janeiro". O autor do perfil faz uma associação esdrúxula entre a condição psíquica da autora e a publicação de seus textos pelo editor ao afirmar que Jardim "pelo visto não se importava com seu [de Maura] estado mental: o editor publicou, até 1964, dez textos da mineira" (Meireles, 2015, p. 204-205).

Com obra e escrita elipsadas do texto, Maura é retomada por uma frase que denuncia a marca do perfil: "Também não imaginavam ["a 
turma do SDJB"] que aquela moça brilhante dali a alguns anos iria cometer um assassinato" (2015, p. 205). O tom de auguro soa como uma espécie de condenação prévia da autora e da própria obra.

O jornalista de $O$ Globo, provavelmente contratado pela editora Autêntica para redigir o perfil que acompanharia o relançamento dos livros, busca na infância de Maura a semeadura de seu caráter e até retoma matérias jornalísticas de cunho machista feitas na década de 1950 (Diário Carioca, 19 dez. 1954) para ilustrar a vida e o comportamento da escritora tida, na matéria e no perfil biográfico, como amante de um milionário, mulher "escandalosa" e "de vícios, acostumada a embriagar-se".

$\mathrm{O}$ tom jocoso predomina em todo o posfácio, como no ponto em que Meireles reputa como "imodéstia" o fato de a escritora ter dado ao filho o nome de Cesarion (Praxedes), "mesmo nome do filho de Cleópatra e de Júlio César". A escolha do nome do filho se voltará contra Maura novamente, quando Meireles comenta uma de suas boutades - a escritora afirma à revista Leitura, em 1968: "Preparo-me para me tornar um dos maiores escritores de língua portuguesa" com uma conclusão maliciosa: "Para quem já batizara o filho de Cesarion, a ambição não era de surpreender" (Meireles, 2015, p. 216).

A citação do laudo em que Maura é definida como uma mulher de "vida desregrada, boêmia", "tendo um amante cada dia ou cada semana", de quem "os homens aproximavam-se sempre com interesses subalternos" é apresentada ao leitor de forma totalmente acrítica pelo jornalista, que a enuncia inclusive com total aquiescência: "Como escrevem os peritos designados pelo juiz para examinar a escritora, já nos anos 1970". Ao fim da citação, Meireles a complementa com uma afirmação sobre em que teria dado a "vida desregrada" da escritora: "Maura gastou a herança do pai até o último centavo". Com esse comentário, Meireles não apenas concorda com os peritos, como também faz uma argumentação demonstrativa contra o que repudia no modelo de vida da, novamente, quatro décadas depois, "periciada".

Esse procedimento se dará em muitas outras vezes. Pinçando do laudo a frase "Sentia-se muito sensual" para usar como epígrafe, Meireles continua em suas ilações: "A moça [Maura] não era propriamente bonita, mas se achava a criatura mais linda - e é verdade que provocava fascínio. Cismava que podia seduzir a 
todos e que todos estavam apaixonados por ela". Ou ainda: "Maura sabia como ser má"; "Maura trancou a porta e começou a fazer escândalo para os porteiros" (Meireles, 2015, p. 216).

Novamente falando pelas palavras dos peritos dos idos de 1970, Meireles transcreve trecho que traz uma frase atribuída à Maura, na qual ela se queixa de sua "inadaptação à vida" e de faltar-lhe "contato com as pessoas". O texto do jornalista, que se segue à epígrafe, iniciase também com uma frase de Maura recolhida de entrevista à revista Leitura (1968) na qual a autora afirma "nada dever literariamente" aos escritores do Suplemento. Meireles passa um pito em Maura por isso, dizendo: "Depois de lançar dois livros com sucesso de crítica, ela agora tinha a audácia de virar as costas para Reynaldo Jardim, Carlos Heitor Cony, Ferreira Gullar e Assis Brasil, de quem tivera apoio dez anos antes, quando estreou nas páginas do Suplemento Dominical do Jornal do Brasil" (Meireles, 2015, p. 217). O jornalista associa esse comportamento que ele reputa como uma "audácia" de Maura às queixas atribuídas à escritora de que se sentia isolada.

A mordacidade com que o jornalista se refere à escritora é digna de rechaço por parte dos leitores e daqueles que estão envolvidos em trazêla novamente à cena literária brasileira. O posfácio aqui comentado não é uma resenha crítica ou uma opinião pessoal publicada na imprensa, como tantas outras, aceitáveis ou refutáveis no campo das opiniões, mas uma espécie de cartão de visita da autora, uma reapresentação de Maura ao público do século XXI, para diante do qual ela retorna, infelizmente, ainda suja da poeira de julgamentos preconceituosos.

Nas raras linhas dedicadas no texto à obra de Maura, Meireles dirá que Hospício é Deus é "fruto de sua passagem pelo Hospital Gustavo Riedel, no Engenho de Dentro, entre o fim de 1959 e começo de 1960", frase seguida por um parêntesis que devolve a escritora rapidamente para o escaninho da "louca": "(onde, ao todo, a autora foi internada pelo menos doze vezes; sem contar outras clínicas)" (Meireles, 2015, p. 218). Não há, no perfil de Meireles, sequer uma citação dos livros de Maura que seja objeto de abordagem ou mesmo de fruição literária.

Em seguida, o jornalista menciona $O$ sofredor do ver, "igualmente elogiado", enfatizando que o tema da loucura continuava na obra. Diz Meireles que, com os contos, "Maura parecia tomar um novo caminho literariamente" baseando-se em resenha de Assis Brasil, no Correio da Manhã, da qual cita um trecho em que o crítico aprecia "a substituição 
do 'eu-confessor' por narrativas em terceira pessoa", reputando a essa operação a ampliação de seu "horizonte criativo" e a libertação por que teria passado a escritora "de sua imediata experiência de vida". Até mesmo a resenha elogiosa de Brasil, um confesso admirador da autora, será usada por Meireles contra Maura. Examinemos:

Maura não baixou a crista. No mesmo artigo na Leitura, ela não esnoba só os amigos, mas também os próprios livros. Diz, com um argumento nada modesto, que Hospício é Deus é uma fase superada: ela sentia-se como Deus diante da criação do Homem, tendo construído seu inferno sem poder se livrar dele. Mas parece ter prestado atenção em Assis Brasil, porque promete um romance para breve, dizendo-se cansada de confissões e "continhos" (Meireles, 2015, p. 219).

De volta ao laudo dos peritos, que reputa como "um dos documentos mais valiosos sobre a biografia de Maura", Meireles não se contém: "Com seu estilo por vezes boquirroto, outras vezes teatralizado, a escritora conta sua vida aos peritos - que veem em sua história 'núcleos psicóticos profundos'. A conclusão a que eles chegam é devastadora" (Meireles, 2015, p. 223). A partir desse ponto o jornalista reproduz a conclusão dos peritos, cuja citação é a maior e mais importante do perfil, adotando, conforme citação anterior, expressões por eles utilizadas, como "estilo teatralizado". Pode-se dizer que o jornalista assina-a novamente, convém repisar, mais de quatro décadas depois de sua anexação ao inquérito.

No espaço de uma resenha não é possível abarcar todas as referências danosas à figura de Maura contidas no texto de Maurício Meireles. É preciso registrar que não se trata aqui de defender a omissão do adoecimento psíquico de que padecia a escritora ou mesmo do crime por ela cometido, uma vez que se pretendia traçar um perfil biográfico. Mas talvez o grande desserviço que Maurício Meireles presta com esse texto seja para com o público, ao encerrar a recepção das obras à condição psíquica e a um episódio infeliz da vida da autora.

Desejamos que os leitores contemporâneos se deem conta de que Maura Lopes Cançado converteu a pecha de louca pela escrita, assenhorando-se desse engessamento simbólico que a aprisionava (e ainda a aprisiona). Sua condição torna-se modelo plástico em sua obra, portanto maleável, e, nesse sentido, 
converte-se em exercício de saudáveis autodeterminação, escolha e liberdade. E é disso que se trata a literatura.

\section{Referências}

MEIRELES, Maurício (2015). Perfil biográfico. In: CANÇADO, Maura Lopes. Hospício é Deus, Diário I. Belo Horizonte: Autêntica.

SCARAMELLA, Maria Luísa (2010). Narrativas e sobreposições: notas sobre Maura Lopes Cançado. Tese (Doutorado em Ciências Sociais) - Universidade Estadual de Campinas, Campinas.

Recebido em $1^{\circ}$ de junho de 2017.

Aprovado em 14 de janeiro de 2018. 